\title{
The Use Potential of Traditional Building Materials for the Realization of Structures by Modern Methods of Construction
}

\author{
Marcela Spišáková, Daniela Mačková \\ Technical University of Kosice \\ Civil Engineering Faculty, Institute of Building and Environmental Engineering \\ e-mail: marcela.spisakova@tuke.sk, daniela.mackova@tuke.sk
}

\begin{abstract}
The sustainable building has taken off in recent years with many investors looking for new and different methods of construction. The traditional building materials can be made out of natural materials, while others can help to lower energy costs of the occupant once built. Regardless of what the goal of the investor is, traditional building materials and their use is on the rise. The submitted paper provides an overview of natural building materials and possible modern building systems using these construction materials. Based on the questionnaire survey is defined the use potential of traditional building materials for the realization of the construction by methods of modern constructions and then are determined the drivers and barriers of traditional materials through using modern methods of construction. Considering the analysis of the achieved results, we can identify the gaps in the construction market in Slovakia and also to assess the perception of potential investors in the field of traditional building materials use, which is the purpose of submitted paper.
\end{abstract}

Key words: natural building material, traditional building material, questionnaire survey, potential, modern methods of construction

\section{Introduction}

Housing is one of the most basic human needs is a key competent in the sustainable development of a community. Sustainability has been defined as economic growth that meets the current generation compromising the opportunity and the potential for future generation needs [1]. In general, sustainable development is divided into three interacting sectors: economic, environmental, and social [2] which resent three pillars of sustainable development [3].

Sustainable construction can influence the short and long term economic targets. The cost reduction is possible thought the using of local suitable materials (lower transportation costs), the energy efficiency of sustainable construction (lower economic demands of realization and operation of construction), etc. 
Social sustainability focuses on the people using the building. Their current and future needs influence the design, which aims to create a highly-flexible plan that allows the building to be easily re-purposed as needs change by the design. A flexible design means the structure can be used longer, preventing the negative impact involved in tearing down an old building and rebuilding a new one.

Measures to address environmental sustainability can include increasing a building's energy efficiency, finding ways for the building to produce its own energy or heat, installing waterreduction measures, finding ways to reduce waste and using of "green" and local building materials. Even the location and orientation of a building can make it more environmentally friendly.
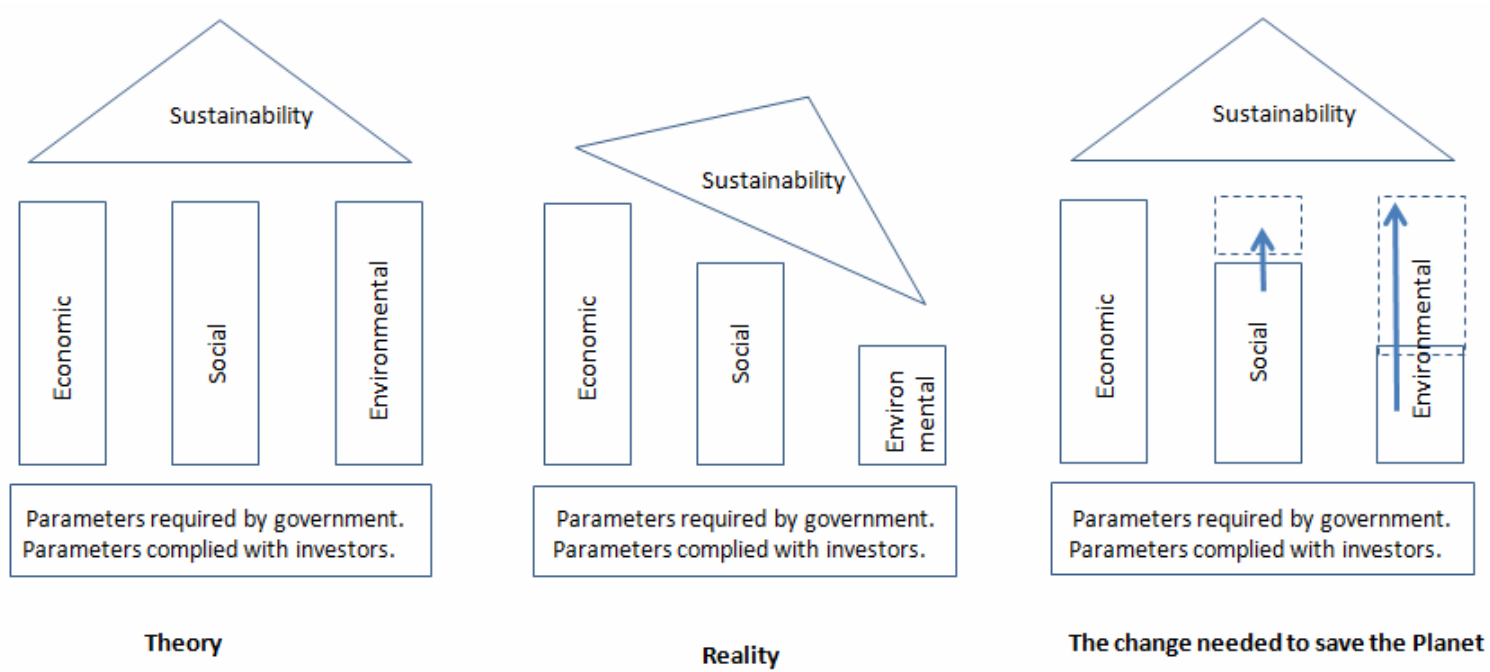

Figure 1: Three pillars of sustainable development [3]

Environmentally preferable products have less negative effects on human health and the environment when compared with competing products that serve the same purpose. In the design phase of construction is necessary to consider the selection of construction technology and building materials and products and prioritize environmentally-friendly forms. It is necessary to think about the theoretical and real sustainable development in the practice [3]. As seen in Fig.1, the individual pillars of sustainable development have different height pillars (influence) at present; therefore, it is necessary to do particular steps to balance their perception. The sustainability must be supported by the strong and the same high pillars in all three areas by the selection appropriate method of construction and construction material within the sustainable design and management of construction. One of the possible ways of sustainable construction is the application of modern methods of construction.

The majority of constructions are still constructed using traditional technology (masonry, concreting). On the other hand, the last few years it has been increased use of modern methods of construction (MMC) for housing, driven by a range of factors including demands for faster construction, skills shortages and sustainability of construction. 
The modern methods of construction primarily involves the manufacture of constructions in factories, with potential benefits such as faster construction, fewer housing defects, reductions in energy use and waste [4] and offer significant potential to minimise construction waste [5] and construction safety risks [6]. The MMC is reasonably common in building construction but are less often used in civil engineering. For civil engineering projects, MMC can include use to pre-cast components or preassembled structure. The wide range of MMC products has various applications in construction practice.

Many of the benefits of using MMC for housing are as yet unproven or contentious. On the other hand, the advantages and disadvantages are closely related to drivers and barriers of prefabrication use [7]. We can divide the main advantages of MMC [4] according the three pillars of sustainable development:

- economic - MMC houses typically have fewer defects and can be built more quickly, components provide a better quality and standards, the construction process can be speeded up by the mass production of prefab components in the factories,

- social - there may be fewer accidents and less impact on local residents during construction, reduces labour intensive activities and provides a safer working environment, designers from different disciplines can work closely together in the early design state to help to reduce abortive work,

- environmental - the houses can be more energy efficient, may involve less transport of materials, and produce less waste.

Typically MMC involves the manufacture of construction parts offsite in a specially designed factory. The two main products of MMC are:

- panels - including ready-made walls, floors and roofs. These are transported to the site and assembled quickly, often within a day. Some panels have wiring and plumbing already inside them, making construction even faster,

- modules - ready-made rooms or their parts, which can be pieced together to make a whole house or flat but are used most frequently for bathrooms or kitchens, where all the fittings are added in the factory.

A range of materials is used for MMC, the most common being wood, steel and concrete, but one of the latest trends in the field of MMC is application of natural (traditional) building material.

\section{Traditional building materials and modern building systems}

While energy consumption is the dominant factor of environmental impact in the operational phase, the most relevant impact factor of building materials is the industrial process. For this reason, sustainable architecture should look for construction materials subject to the least possible number of technological manipulations, possibly of renewable origin or completely recyclable or reusable at the building end-of-life, and produced on-site or nearby to avoid long distance transportation [8]. Therefore, it is suitable to use traditional materials (renewable sources) by modern construction methods (reduce a number of technological operations). Traditional building materials are of natural origin. These fulfillments are no 
longer perceived as unattainable, as testified by an increasing market of renewable, natural, recycled building products and systems.

\subsection{Traditional building materials}

The natural materials, such as stone, wood, straw, sheep's wool, fibers - hemp, cork and clay present the traditional construction material. But, in the last fifteen years, especially in Europe and the USA, there has been an upsurge of interest in natural and unconventional construction materials.

Traditional (natural) building materials can be used as:

- structural materials - load bearing construction (wood, stone, rammed earth, straw bales, clay bricks, etc.)

- insulation materials - sheep wool, fibers - hemp, cork, etc.,

- complementary materials - realization of plastering, painting, flooring (clay, cork, etc.).

Stone is one of the major construction materials. It is a highly durable, low maintenance building material with high thermal mass. It is versatile, available in many shapes, sizes, colours and textures, and can be used for floors, walls, arches and roofs. Stone blends well with the natural landscape, and can easily be recycled for other building purposes.

Wood is the oldest material used by humans for constructional purposes, after stone [9]. Despite its complex chemical nature, wood has excellent properties which lend themselves to human use. It is readily and economically available, easily machinable, amenable to fabrication into an infinite variety of sizes and shapes using simple on-site or off-site building techniques, exceptionally strong relative to its weigh, a good heat and electrical insulator and is a renewable and biodegradable resource.

In construction industry, straw occurs most frequently in the form of straw bales which are used either as infill cladding for wood framed buildings or as load-bearing construction, which can transfer load on the roof, without adding any supporting structures. It is also possible straw used as thermal insulation of roofs, but the best with it already foreseen in the design of the building.

The hemp presents a renewable and regrowing construction material. The plant contains substances that repel insects, and therefore to protect it requires no insecticides. Nowadays, hemp is used mainly for insulating materials in floors, walls and roofs as a high quality product, containing hemp fibers $(85 \%)$, fibers $10 \%$, and $5 \%$ sodium carbonate, which is added as a fire protection.

Sheep's wool is natural, ecological and renewable construction material. Sheep's wool is mainly used as an insulation material for the insulation of envelope or roof structures. Wool insulation is realized by technology of vertical laying sheep's wool without using any binders. Cork serves many purposes. Products made of cork are broadly applicable throughout the building. In the past, most used as thermal insulation of cold stores. Nowadays it is used as a contact thermal insulation, insulation for ventilated facades of buildings and roof insulation. 
Its soundproofing qualities are most used in the construction of floors, walls, partitions and ceilings.

Clay is the oldest natural building materials. It consists of a mixture of clay, sand, and dust. It may also contain coarser particles (gravel) or organic material. The most common way to use clay in the construction is in the form of clay bricks or clay in the form of ramming. In addition, it presents the filling of half-timbered construction and wood framed construction or as a clay plaster.

Each of traditional construction material is characterized by physical properties that determine its use in construction sector (Tab.1). The natural materials are the most common use as thermal insulating material.

Table 1: Properties and usage of natural materials, Source: authors

\begin{tabular}{cccc}
\hline $\begin{array}{c}\text { Natural } \\
\text { material }\end{array}$ & $\begin{array}{c}\text { Density } \rho \\
{\left[\mathrm{kg} / \mathrm{m}^{3}\right]}\end{array}$ & $\begin{array}{c}\text { Coefficient of } \\
\text { thermal conductivity } \\
\lambda[\mathrm{W} /(\mathrm{mK})]\end{array}$ & Usage \\
\hline Straw & $90-180$ & $0,044-0,063$ & $\begin{array}{c}\text { load bearing construction } \text { - straw } \\
\text { bale, infill cladding for wood framed } \\
\text { buildings, roofing } \\
\text { load bearing construction - wooden } \\
\text { framed construction, roofing, } \\
\text { flooring, ceiling, etc. }\end{array}$ \\
Hemp & $900-1000$ & $0,075-0,25$ & $\begin{array}{c}\text { insulation of roof, floor fillings, fiber } \\
\text { composites }\end{array}$ \\
Sheep's wool & $13-25$ & $0,038-0,05$ & $\begin{array}{c}\text { insulation of roof, walls, floors, infill } \\
\text { cladding for wood framed buildings, }\end{array}$ \\
Cork & $45-150$ & $0,035-0,058$ & $\begin{array}{c}\text { contact insulation system, floor } \\
\text { insulation, interior equipment }\end{array}$ \\
Clay & $1000-2200$ & $0,20-0,95$ & $\begin{array}{c}\text { infill cladding for wood framed } \\
\text { buildings, clay plasters }\end{array}$ \\
\hline
\end{tabular}

Natural building materials can be used by modern way as the building systems.

\subsection{Modern building systems using the traditional construction materials}

Currently, there has been an upsurge of interest in natural building material used by modern technologies and computer-controlled production. Framed building or modern building methods using the traditional material are still popular and have many benefits compared the conventional construction methods (masonry, concrete). The most used natural building techniques are hempcrete, cob, earthbags, straw bale construction, clay bricks, rammed earth and wooden construction (ei. log houses). 

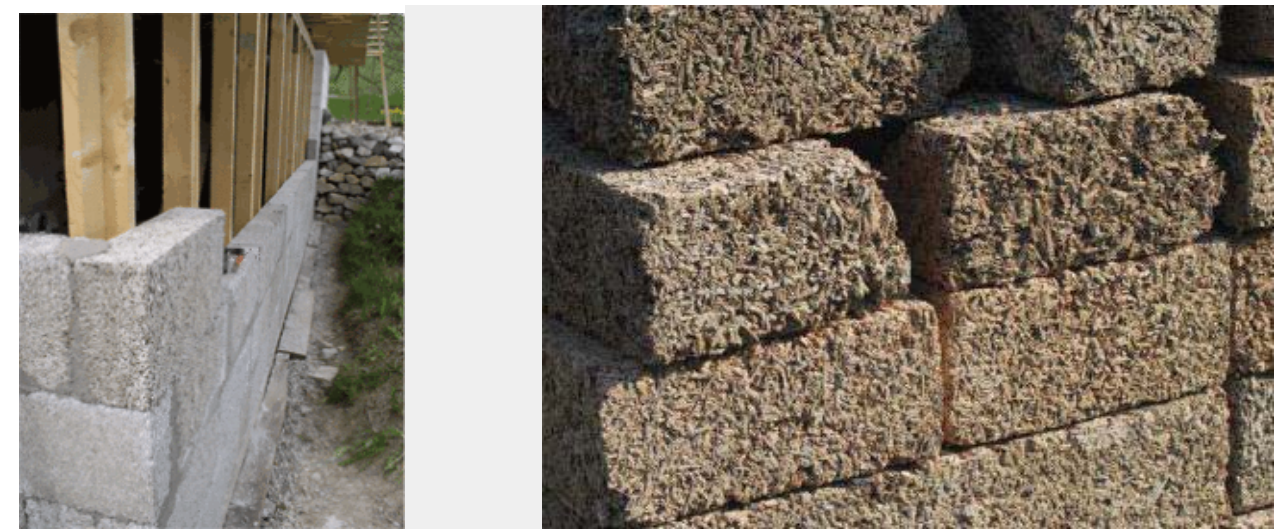

Figure 2: Thermal insulation by Hempcrete panels and prefabricated Hempcrete panels [10]

Hempcrete is a bio-composite made of the inner woody core of the hemp plant mixed with a lime-based binder. The hemp core has a high silica content which allows it to bind well with lime. This property is unique to hemp among all natural fibers. The result is a lightweight cementitious insulating material weighing about a $1 / 7-1 / 8$ of the weight of concrete. It is not used as a structural element, only as insulating infill between the frame members though it does tend to reduce racking. All loads are carried by internal framing. Wood stud framing is most common making it suitable for low-rise construction [10].

A construction method cob is the process of using the cobs to build monolithic walls with building materials such as straw and moist earth [11]. The cobs are small bricks of material, formed out of fibrous materials such as clay, sand, and straw. A stiff mud is created out of these materials, and formed into the building blocks. When the building is created, a concrete or stone foundation is laid, then the cobs are put together and mashed on top of the foundation, building a monolithic wall. These building techniques create thick walls. Each layer needs to have time to solidify before the next layer is applied, and sharp tools can be used to shave off irregularities. Cob system has many benefits. It has significant thermal properties and can accumulate heat, is ease of building, can be easily integrated with other techniques and it is easy to create details such as windows and other decorative details in the structure.

Fabric sacks filled with soil are known as earthbags, and they are great building materials for constructing domes and walls. But, in recent years, they have been used as a natural construction method. Using earthbags for home construction is still a newer system. This technique has many advantages - short construction duration, easy construction technology, etc.. When buildings are constructed with earthbags, the soil is moistened before it is placed in the bag. Then, the bags are carefully placed onto a foundation, and a hand tamper is used to compress the bags together. Sometimes earthbags are used as a foundation for other natural building techniques. For example, the earthbags may be a good foundation, and then bale, straw, or cob materials are used for the rest of the structure.

Straw bale construction consists of baled straw from different types of wheat for insulation and usually covered with stucco as an exterior finish. Straw bale forms can be used for 
residential as well as light commercial applications such as schools, community centres and other low rise buildings.
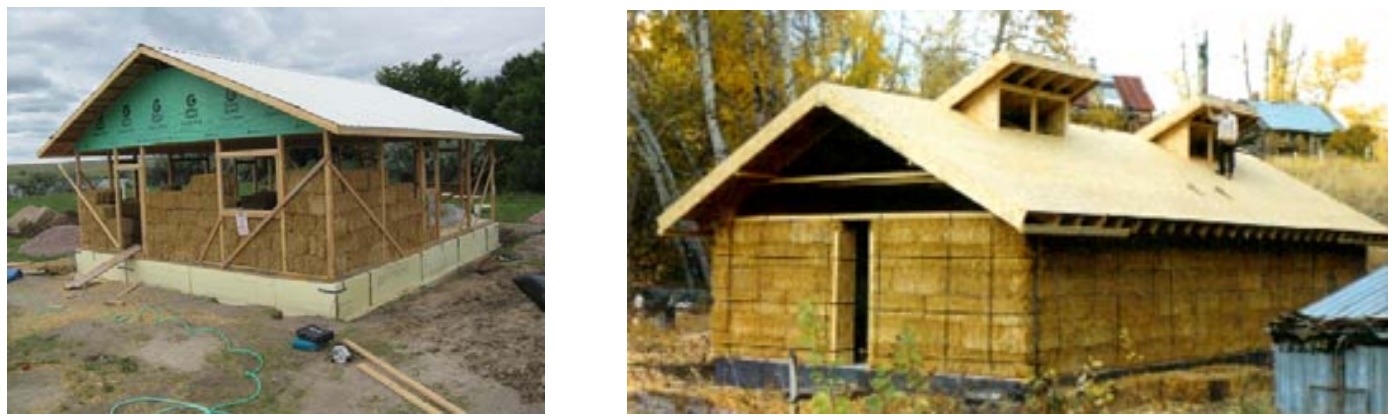

Figure 3: Straw bale as a non load-bearing construction and load-bearing construction (system Nebraska) [13]

We know two main methods of building a home using straw bale construction [12]. The first is post and beam construction, where the structural support is achieved by using heavy timber framing all around the bales (Fig.3). This method is usually preferred in damp locations. The bales cannot get wet during the construction process therefore with the post and beam method, the roof can be built first and the straw bale insulation can be implemented later. The second method is called the Nebraska style straw bale construction (Fig.3). It gets its name from the original straw bale homes that were originally built in Nebraska, where in this method the weight of the roof is supported by the bales of straw. Straw bale homes look the same as any other type of home due to the finish on the exterior and interior.

Rammed earth walls (Fig.4) are constructed by ramming a mixture of selected aggregates, including gravel, sand, silt and a small amount of clay, into place between flat panels called formwork. Traditional technology repeatedly rammed the end of a wooden pole into the earth mixture to compress it. Modern technology replaces the pole with a mechanical ram. Stabilised rammed earth is a variant of traditional rammed earth that adds a small amount of cement $(5-10 \%)$ to increase strength and durability. Stabilised rammed earth walls need little added protection but are usually coated with an air-permeable sealer to increase the life of the material - it varies with circumstance.
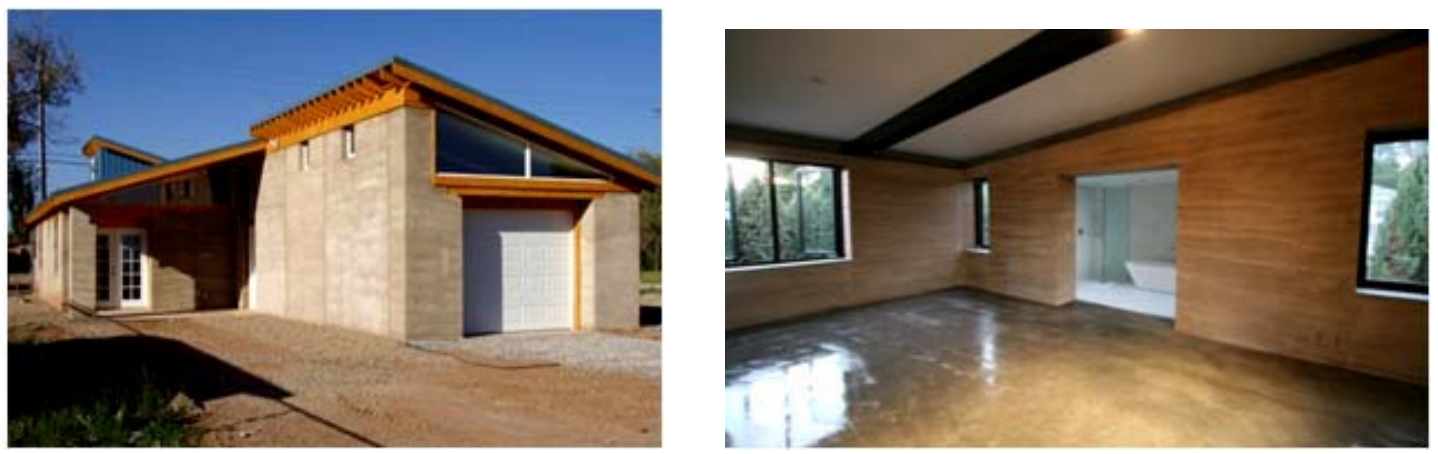

Figure 4: Family house constructed by technology rammed earth [14] 
The most used natural construction material is wood applied in heavy framed, light framed or $\log$ construction. Light wood framed construction is one of the most popular types of building methods for homes in the United States and parts of Europe. We know the construction system where the wood presents load-bearing construction and other natural materials (straw bales can) presents infill cladding.

\section{Research materials and methodology}

The interest in natural building material used by modern technologies which have lower embodied energy than conventional ones and help reducing the exploitation rate of non renewable resources is increasing [14]. These technologies are usually used for construction of family houses. The aim of submitted paper is finding out the use potential of traditional building materials for the realization of construction by modern methods of constructions.

The research was realized through the questionnaire survey. A questionnaire was developed and administered to 463 respondents - potential investors for construction of houses in Slovakia. The survey was conducted over a period of 3 months in 2015. There were 102 respondents with a response rate of $22,03 \%$.

The questionnaire, consisting of 13 questions, was designed to address the following issues:

- general information about respondents,

- identification of respondents' awareness about the traditional building materials and systems usage in Slovakia

- determining of drivers and barriers of using traditional materials by modern methods of construction.

In the questionnaire, the respondents were requested to assign an appropriate rating on a scale of 1-5, from the highest to the lowest level, against each factor to reflect the importance of the factors in each question. The means of the factors were calculated based on the following weightings:

- "Least important" was given a negative two (-2) weight,

- "Less important" was assigned a negative one (-1) weight,

- "Neutral” was given a zero (0) weight,

- “Important" was assigned a positive one $(+1)$ weight,

- “Most important" was given a positive two $(+2)$ weight.

The mean of each factor was calculated by the following equation.

Mean of factor:

$$
\overline{\mathrm{x}_{\mathrm{i}}}=\frac{\sum_{\mathrm{j}=1}^{5} \mathrm{~W}_{\mathrm{j}} * \mathrm{f}_{\mathrm{ij}}}{\sum_{\mathrm{j}=1}^{5} \mathrm{f}_{\mathrm{ij}}}
$$

where, $\mathrm{W}_{\mathrm{j}}=$ weights of the degree of importance $\mathrm{j}$ of factors $(-2,-1,0,+1,+2), \mathrm{f}_{\mathrm{ij}}=$ corresponding frequencies of the degree of importance $j$ of factor $i, \sum_{j=1}^{5} f_{i j}=$ total number of respondents. 
The ranking of the factors were then based on the means calculated using the above equation. The higher the mean, the higher the ranking.

\section{Results and discussion}

Questionnaire survey was attended by 102 potential investors for construction of houses. $40,9 \%$ of respondents are going to build or likely going to build the family house in next five years. Almost $73 \%$ of respondents prefer (Fig. 5) to build a house with conventional construction materials (ceramic blocks, porous concrete blocks [16]) compared to natural materials (wood, straw, clay, etc.).
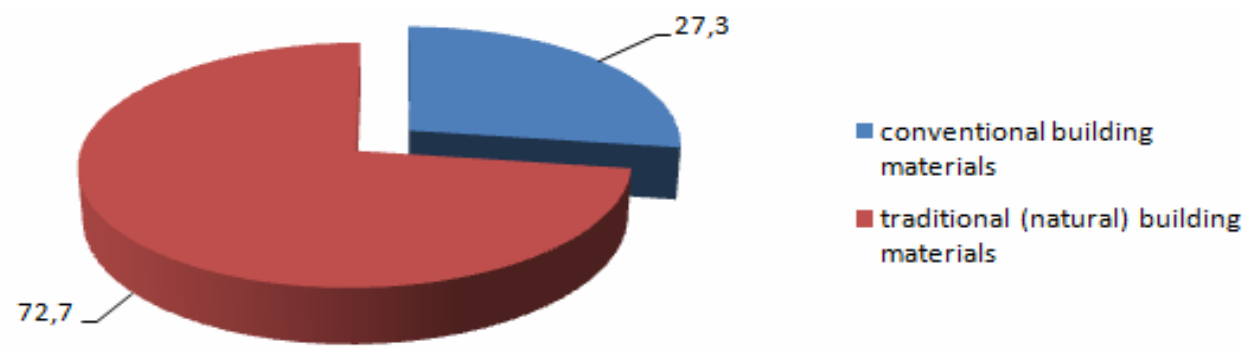

Figure 5: Material preferences of respondents to build a family house (in\%)

We assumed that the respondents' lack of interest in traditional building materials, respectively modern building system using the traditional materials is based on lack of information and knowledge about them applicability. Results of the questionnaire survey confirmed our assumptions.

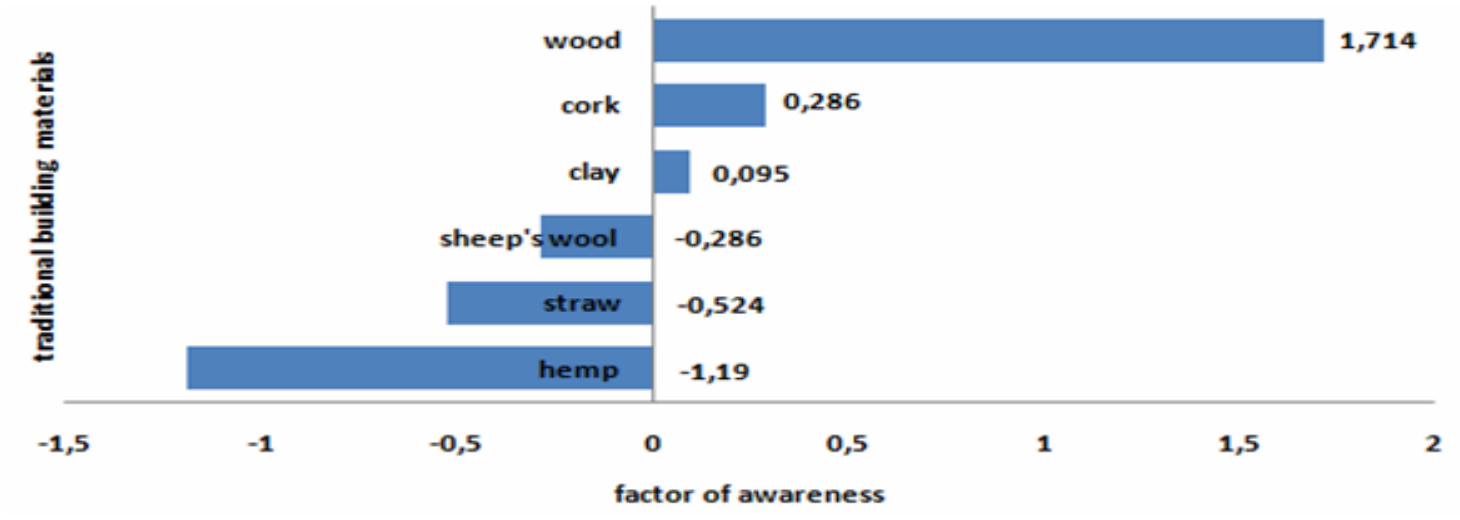

Figure 6: Factor of respondents' awareness about the traditional building material

The best known natural material is wood $(1,714)$, as well as the wooden construction $(1,905)$. Not surprisingly, other natural building materials are for investors in Slovakia rather unknown (Fig.6). On the other hand, respondents recognized (Fig.7) the clay brick construction method (in the past Slovakia widely used technology) and straw bales construction method. 


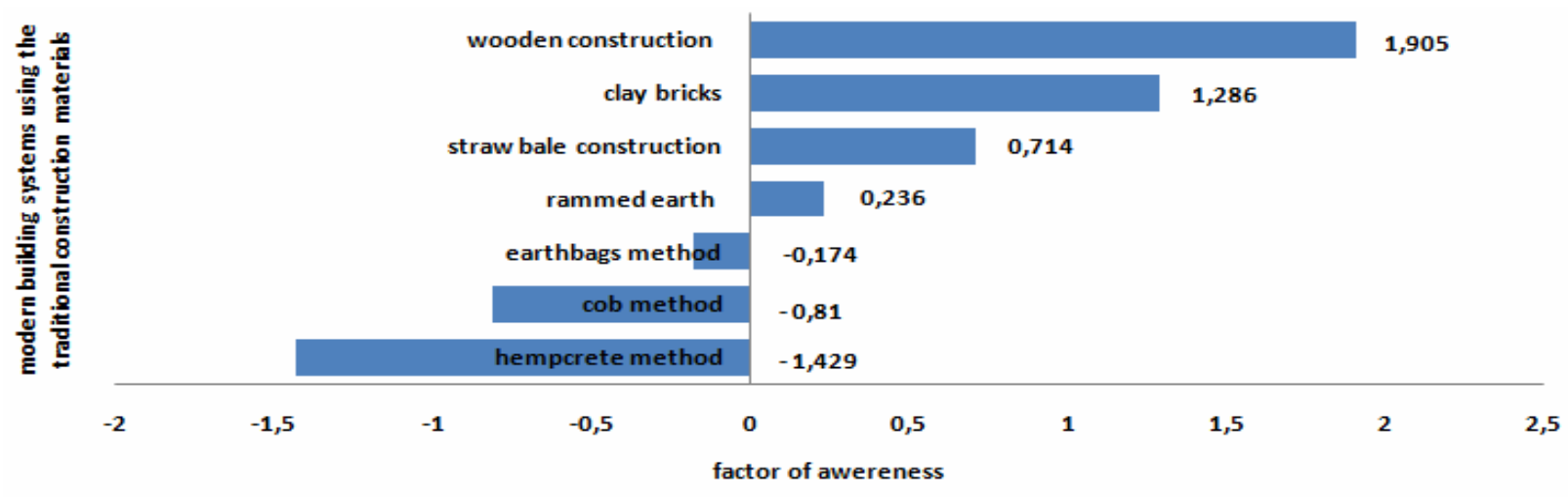

Figure 7: Factor of respondents' awareness about the modern building systems using the traditional construction material

The last part of questionnaire survey was focused on the determining of drivers and barriers of using traditional materials by modern methods of construction. Based on respondents' answers were processed the ranking of drivers and barriers for use of these technologies (Tab.2).

Table 2: Ranking of drivers and barriers of using traditional materials by modern methods of construction, Source: authors

\begin{tabular}{|c|c|c|}
\hline Ranking & Drivers & Barriers \\
\hline 1 & construction costs & $\begin{array}{c}\text { availability of conventional building } \\
\text { material }\end{array}$ \\
\hline 2 & quality of construction technology & $\begin{array}{l}\text { continuous development of new } \\
\text { construction technologies and materials }\end{array}$ \\
\hline 3 & $\begin{array}{l}\text { insulating properties of natural } \\
\text { materials }\end{array}$ & lack of natural construction skills \\
\hline 4 & availability of technology & public attitude \\
\hline 5 & references about the technology & uncertainty about demand \\
\hline 6 & duration of construction & lack of construction professionals \\
\hline
\end{tabular}

Not surprisingly, recent research [17] indicates that cost is the most important factor for investors in selection of construction methods or technologies for building projects. The respondents confirmed our assumption. The most important factors for selection of using traditional materials by modern methods of construction are the construction costs and quality compared to conventional methods of construction. The third most important factor is insulating properties of natural materials. Considering this, the investors are also interested in operating costs of buildings. On the other hand, it is an advantage because natural building materials have excellent thermal insulation properties. The least important factor for respondents is the duration of construction. However, application of traditional materials by modern methods of construction enables reduction of construction time. 
Among the most significant barriers to using of traditional materials by modern methods of construction belong availability of conventional building material and continuous development of new construction technologies and materials. The conventional building materials are widespread at the construction market in Slovakia. The investors are satisfied with their properties and producers are constantly trying to develop new and better building materials based on the conventional principles. This is closely related to public attitude to use of natural materials. The investors still do not prefer the sustainable natural construction materials but proven known methods and technologies. Subsequently, the construction market is not forced to improve the construction skills and professionals dealing with using of traditional materials by modern methods of construction.

A detailed analysis of drivers and barriers ranking confirmed our assumption - construction market adapts to investors requirements $[18,19]$. While investors not require the use of natural materials, the construction market will not offer them. On the other hand, public awareness on the use of traditional materials (such as sustainable and renewable natural resource) is currently insufficient. It should be emphasized that according to respondents' answers, currently it is increasing interest in the construction of traditional materials (in the scale -2 to +2 is the interest rate 0,91 ). Respondents also confirmed the positive impact of the use of natural materials in all areas of the environment (in the scale -2 to +2 is the influence rate 1,29$)$.

\section{Conclusion}

Sustainable construction aims to meet present day needs for housing, working environments and infrastructure without compromising the ability of future generations to meet their own needs in times to come. It incorporates elements of economic efficiency, environmental performance and social responsibility - and contributes to the greatest extent when architectural quality, technical innovation and transferability are included. One of the sustainable construction ways is to prefer the traditional construction materials, such as stone, wood, straw, sheep's wool, fibers - hemp, cork and clay by the new modern methods of construction. The aim of paper was the based on the questionnaire survey to define the potential use of traditional building materials for the realization of the construction methods of modern constructions. The respondents of questionnaire survey determined the drivers and barriers of traditional materials by using modern methods of construction and assess the public interest in natural building material usage.

\section{Acknowledgements}

This work has been supported by Grant Agency of Slovak Republic to support of project VEGA No. 1/0677/14 "Research of construction efficiency improvement through MMC technologies".

\section{References}

[1] World Commission on Environment and Development (WCED). (1987). Our common future. Oxford University Press : Oxford

[2] Keiner M. (2005). History, definition(s) and models of sustainable development. ETH Zurich 
[3] Tazikova A. (2014). Sustainability of existing buildings obtained by reconstruction. In Innovative approaches to the design and management of buildings reconstruction, Kosice: TUKE

[4] Modern methods of house building. (2003). Postnote, London

[5] Waste and resource programme (2007). Current practices and future potential in modern methods of construction. Banbur, Oxon: WRAP

[6] Strukova Z. (2009). Specific perception of safety risks of construction projects. In Innovative approach to modelling of intelligent structural elements in construction, Kosice: TUKE

[7] Lovel H. \& Smith S. J. (2008). Agencement in housing markets: The case of the UK construction industry. Geogorum. 41(3), 457-468

[8] Melia P., Ruggieri G., Sabbanimi S. \& Dotelli G. (2014) Environmental impacts of natural and conventional building materials: a case study on earth plasters. Journal of cleaner production. $80,179-186$

[9] Kozlovska M., Strukova Z. \& Kaleja P. (2015) Methodology of cost parameter estimation for modern methods of contruction based on wood. Procedia Engineering 7th Scientific-Technical Conference on Material Problems in Civil Engineering, MATBUD 2015; Cracow University of Technology; Krakow; Poland; 22 - 24 June 2015

[10] http://www.americanlimetechnology.com/what-is-hempcrete/

[11] http://www.strawbalecentral.com/techniques3.html

[12] http://www.fibertec.com/as-green-as-it-gets-straw-bale-homes/

[13] http://earthzine.org/

[14] http://www.yourhome.gov.au/materials/rammed-earth

[15] Pacheco-Torga F. \& Jalali S. (2012). Eco-efficient construction and building materials research under the EU Framework Programme Horizon 2020. Construction and building materials, 51(1), 151-162

[16] Baskova R. \& Sicakova A. (2014) Modern technologies of architectural concrete. In Improving the efficiency of construction through MMC technologies - Proceedings of scientific papers Kosice: TUKE

[17] Jaillon L., Poon C. S. \& Chiang Y. H. (2009) Quantifying the waste reduction potential of using prefabrication in building construction in Hong Kong. Waste Management. 29 (1), pp 309-320

[18] Lesniak A. \& Plebankiewicz E. (2015) Modelling the decision-making process concerning participationin construction bidding. Journal of Management in Engineering. 31 (2)

[19] Zima K. The concept of investment decision support model using fuzzy set theory. In AIP Conference Proceeding 11th International Conference of Numerical Analysis and Applied Mathematics 2013, ICNAAM 2013; Rhodes; Greece; 21 - 27 September 2013 AIP Publishing LLC 